\title{
A prosa da vida
}

LUIZ TYLLER PIROLA

LUIZ TYLLER PIROLA é professor assistente de Literatura Brasileira do Departamento de Letras do Instituto de Ciências Sociais da Universidade Federal de Ouro Preto.
1 G. W. F. Hegel, "A Arte Clássica e a Arte Romântica", in Estética, trad. Orlando Vitorino, Lisboa, 1972, tomo IV, p. 297.

2 Miguel de Cervantes Saavedra, Dom Quixote de la Mancha, trad. Viscondes de Castilho e Azevedo, São Paulo, Círculo do Livro, s/d., pp. 514-5.

3 Idem, ibidem, p. 524.
Por largo tempo a história da literatura ocidental conheceu romances escritos em versos retratando a idealização de uma vida aventurosa consubstanciada nos ideais da cavalaria andante. Essas histórias mirabolantes, mesmo para o homem do séc. XVI, convivendo com um mundo em expansão, não mais satisfazem. Trata-se de um pragmatismo nascido dentro da própria literatura. Aqui, neste caso específico, tomando-se a necessidade da arte particularmente, embora de modo a representá-la no geral. Um gênero - as novelas de cavalaria - que estava por demais distanciado da realidade. A tal ponto que a comparação externa tornou-se então possível, ultrapassando o postulado teórico da interioridade comparativa que vem desde Aristóteles. A reação literária justamente marca a passagem da poesia do eu para a prosa da vida.

“(...) Dom Quixote possui uma nobre natureza que o espírito de cavalaria leva à loucura logo que, na sua busca de aventuras, esbarra com as condições firmes e imutáveis da realidade exterior (...)"(1).

Dom Quixote é o arauto de um mundo novo. Não ele personagem, mas a sua concretização transparente no romance. $\mathrm{O}$ homem que fica louco por muito ter lido novelas de cavalaria é coerente dentro de sua desgraçada comicidade. Convivem a loucura romanesca e a prosa da vida na figura do fiel escudeiro Sancho. O Cavaleiro da Triste Figura a todo momento toma contato com os imorredouramente lapidares rifões cunhados por Sancho, atinentes à praticidade do cotidiano.

“(...) - Trabalhosa vida e a que passamos e vivemos, senhor meu, os que somos escudeiros de cavaleiros andantes; pode-se dizer, na verdade, que comemos o pão ganho com o suor do nosso rosto, que foi uma das maldições que Deus deitou aos nossos primeiros pais.

- Também se pode dizer - acrescentou Sancho - que o comemos com o gelo dos nossos corpos, porque quem é que tem mais calor e mais frio do que os míseros escudeiros da cavalaria andante? E ainda não era mau se comêssemos, pois que lágrimas com pão passageiras são (...)"(2).

Somente o mestre da metalinguagem poderia romper com a tradição de maneira tão desabridamente sutil. Parece que os maneiristas conseguem dizer suas idéias de um modo a que o leitor se surpreenda pelo que está ali expresso.

“(...) Enquanto Dom Quixote se demorava a ajudar Sancho a trepar à árvore, tomou o dos espelhos o campo que lhe pareceu necessário; e julgando que o mesmo teria feito Dom Quixote, sem esperar som de trombeta nem outro sinal que os avisasse, voltou as rédeas ao cavalo, nem mais ligeiro, nem de melhor aparência que Rocinante, e a todo o seu correr, que era um meio trote, ia a encontrar o inimigo; mas, vendo-o ocupado com a subida de Sancho, sofreou as rédeas, e parou a meio caminho, ficando o cavalo agradecidíssimo, porque já se não podia mover. Dom Quixote, que imaginou que o seu inimigo vinha por af fora voando, enterrou com alma as esporas nos magros ilhais de Rocinante e de tal maneira o espicaçou, que diz a história que foi 


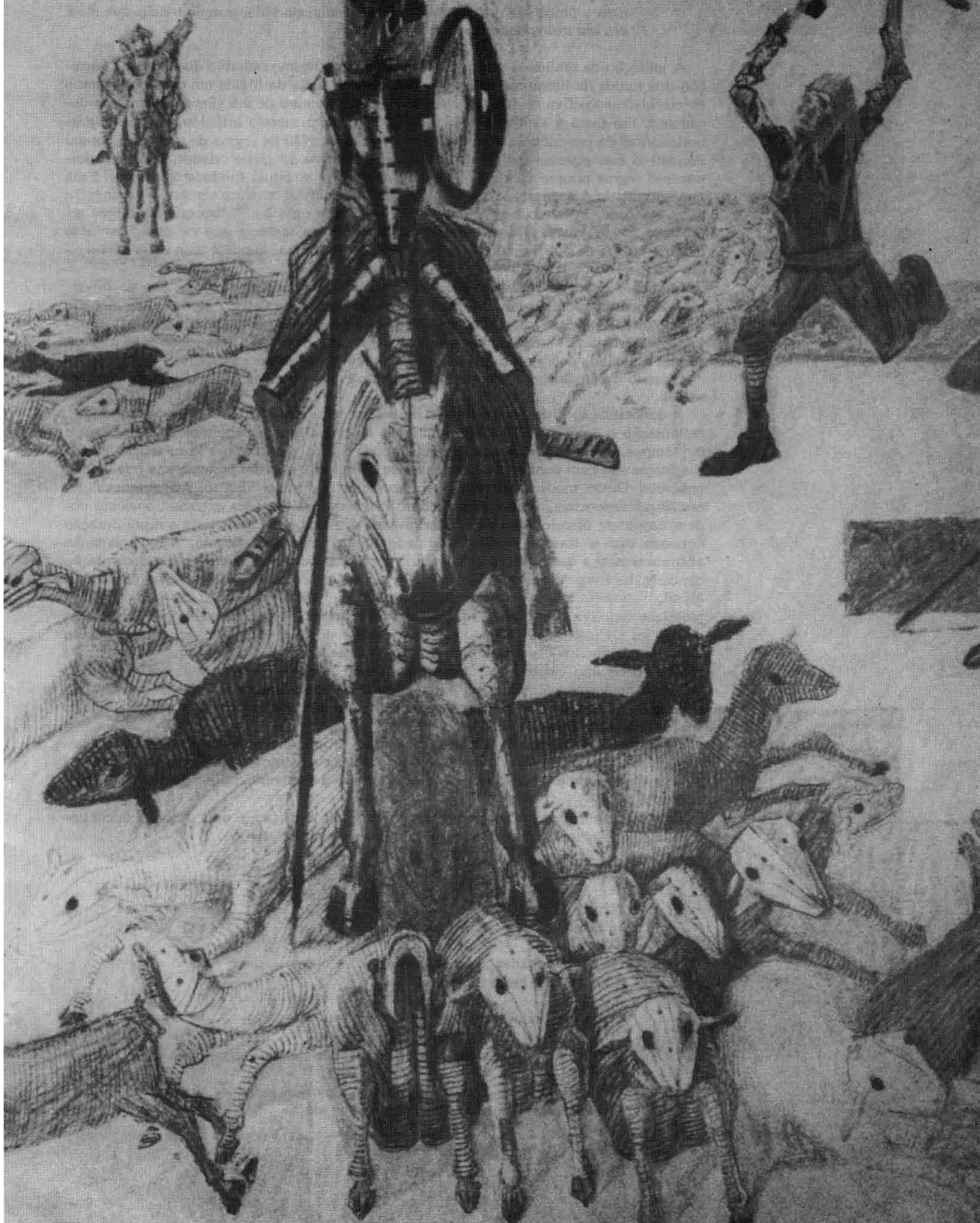


essa a única vez que ele galopou em toda a sua vida, porque o mais que dava era um trote declarado (...)'(3).

À imitação da realidade possf́vel junta-se o subjetivismo objetivo do artista na correção dos rumos da literatura. Seu texto é a representação da lógica em confronto com a objetividade subjetiva do homem que fica louco por causa de um gênero romanesco decadente. Em meio a esta aparente falta de lógica do mundo artístico, existem regras norteadoras da prevalência deste ou daquele gênero. Não as regras de qualquer manual normativo mas aquelas indiź́veis do manual subjetivo do gênio criador. São verdadeiramente regras porque lhes antecedem a formação conceitual fundada nas idéias. Essa particularidade é apenas aparente pois as idéias estéticas tendem sempre a abranger a universalidade. Portanto bem diferente de uma mera opinião. "Uma opinião é uma representação subjetiva, um pensamento qualquer, uma fantasia que eu posso ter dum modo e outros de outro modo; uma opinião é coisa minha, nunca é uma idéia universal que existia em si e por si"(4).

Enquanto as regras artísticas são a representação da verdade pelo que têm de universal - à medida que um maior número de pessoas pense do mesmo modo ou de maneira semelhante, a verdade se estabelece; claro está que, pessoas, aqui, sensíveis às manifestações artísticas - uma mera opinião não passará nunca de uma representação conceitual esvaziada pela ilusão que tem de pretender representar a verdade.

Quando a opinião pretende ser ela mesma universal trata-se af da afirmação da autoridade.

A conceituação artística é o oposto de tudo o que significam regras preestabelecidas, restauração e autoridade. As regras internas da arte é que permitem reações de tempos em tempos, quando mudam as condições gerais para a apreciação e fazer artísticos. Essas forças são bem conhecidas pelo que têm de exterior e assim pertencerem à realidade concreta. Desse modo interferem, não decidem, nos rumos das formas artísticas. As mudanças essenciais, apesar de sofrerem fortemente as pressões externas, somente podem acontecer direcionadas pela interioridade artística, tendo em vista a representação concreta que se torna o conjunto de dado gênero já então esgotado. A representação abstrata temática das novelas de cavalaria supera-se pelo acúmulo de sua representação concreta: os livros de cavalaria. Cervantes fez uma mediação entre a poesia do eu que, afinal, é também a sua obra e a prosa da vida que são os fatos exteriores e a própria realidade objetiva como um todo. Não sua conciliação, porque são realidades contrárias de per se. Os interesses na prosa da vida assim podem ser chamados pelo que se espera das coisas e objetos organizados e conceituados para servir. Ao passo que no mundo da subjetividade não existem interesses porque não se espera interesse algum no sentido utilitário do termo. A práxis da exterioridade objetiva distancia-se da práxis artística porque só existe razão da aplicação do termo aqui usado à medida que práxis, em arte, significa o fazer artístico.

Idéias muito próximas de um anarquismo que propõe o fim da autoridade e a desobediência a regras existentes, não fosse a arte avessa a ideologias políticas determinadas por ser ela mesma um constante exercício político da subversão dos valores estabelecidos.

O poeta desobedece e, mesmo quando peca pela omissão, é uma desobediência cometida contra as leis não-escritas e subjacentes do mundo artístico.

\section{Lisbon Revisited}

Não: Não quero nada.

Já disse que não quero nada.

Não me venham com conclusões!

A única conclusão é morrer!

Tirem-me daqui a metafísica!

Não me apregoem sistemas completos, não me enfileirem conquistas.

4 G. W. F. Hegel, "Introduçâo à Historia da Filosofia", in Os Pensadores, trad. Antonio Pinto de Carvalho. Såo Paulo, Abril Cultural, 1974, v. 30. p. 336 .
Das ciências (das ciências, Deus meu, das ciências!)

Das ciências, das artes, da civilização moderna!

Que mal fiz aos deuses todos? 

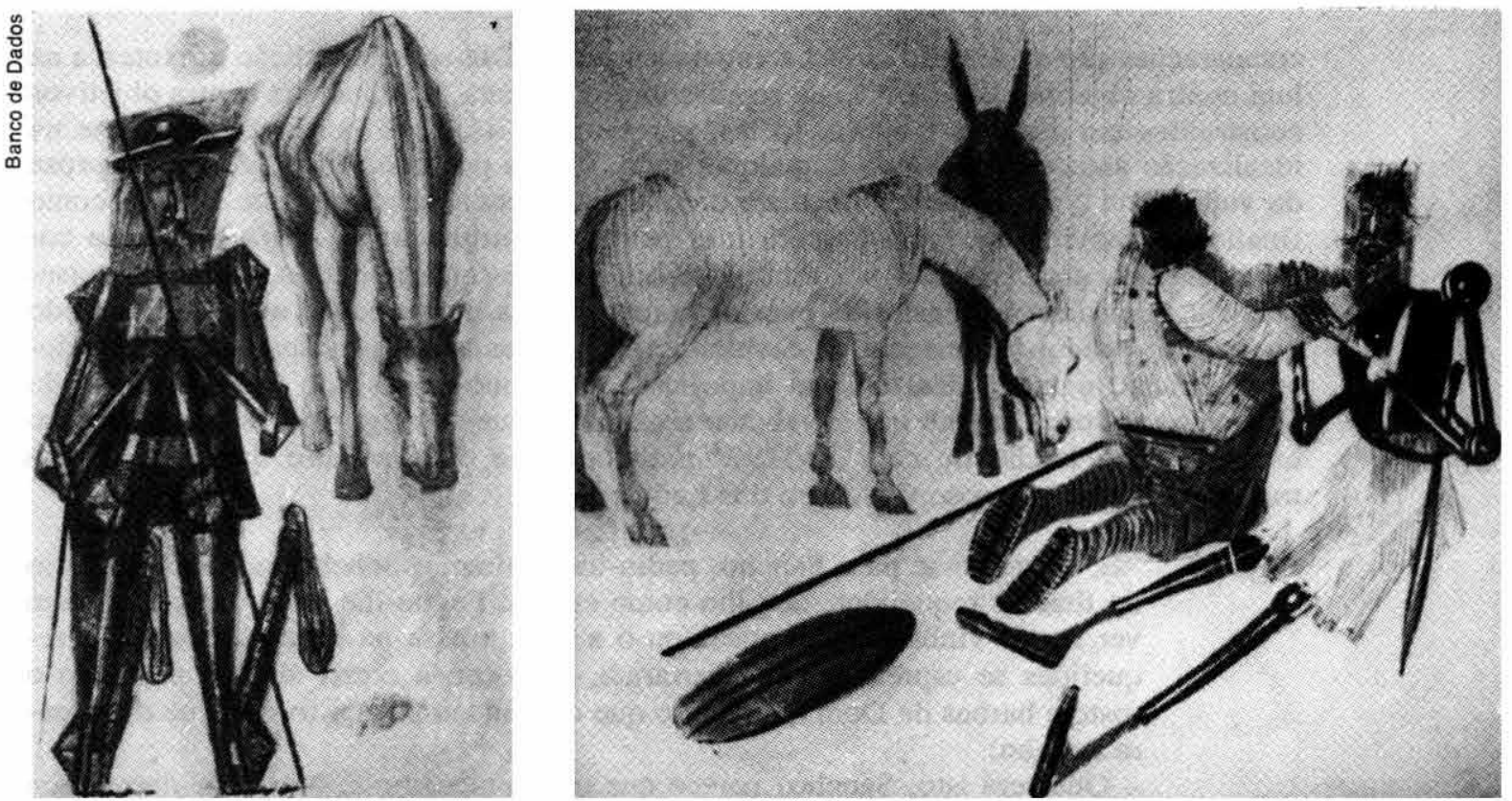

Se têm a verdade guardem-a!

Sou um técnico, mas tenho têcnica só dentro da técnica Fora disso sou doido, com todo direito a sê-lo.

Com todo direito a sê-lo, ouviram? $(\ldots)^{(5)}$.

O descomprometimento ideológico é subversivo e a mais singela práxis política que o homem poderia conceber: o poeta na luta contra o acaso enche o papel em branco com os postulados de um programa anárquico. Afinal para a sociedade a inutilidade se diz do significado próprio da palavra. $\mathrm{O}$ objeto inútil veicula idéias porque estas lhe são inerentes e não porque se quer achar aqui uma serventia ao que por sua própria natureza não tem préstimo.

No Dom Quixote as regras da cavalaria andante são ridicularizadas, simbolizando a aproximação da literatura com o viver cotidiano. Obviamente nunca conivência, antes denúncia ainda que por meios travessos como se a sociedade e as regras dela fossem a cavalaria andante e suas regras. No hilariante trecho que pretende explicar a diferença entre afronta e agravo, o que resta é a crítica de certa ordem moral galante das coisas vigentes na sociedade.

“(...) As mulheres, as crianças e os eclesiásticos não podem defender-se: não podem ser afrontados, porque entre o agravo e a afronta há a seguinte diferença: a afronta só vem da parte de quem a pode fazer e a faz e a sustenta; 0 agravo, esse pode vir de qualquer parte, sem que afronte. Exemplo: está uma pessoa na rua muito descuidada; chegam dez bem armados e dão-lhe uma sova de pau; ele desembainha a espada e faz o seu dever; mas opōe-se a multidão dos seus adversários, e não deixa executar a sua intenção, que é de vingar; fica esse homem, portanto, agravado, mas não afrontado. Outro exemplo: está um homem de costas voltadas; chega outro, dá-lhe duas pauladas e foge; o primeiro segue-o mas não alcança; o que foi espancado recebeu agravo, mas não afronta, porque a afronta precisa ser sustentada. Se o que deu as pauladas, ainda que as desse por traição, metesse depois a mão à espada e parasse para fazer frente ao seu inimigo, ficaria o outro juntamente agravado e afrontado; e, assim, segundo as leis do maldito duelo, o agravo não é necessariamente afronta, porque nem as crianças, nem as mulheres, nem os sacerdotes, podem sustentar qualquer agravo que fizerem; carecem de armas ofensivas e defensivas (...)"(6).

Esta grande metáfora arquetípica em que se transformou Dom Quixote tem levado a
Nesta página e na 155, desenhos de Candido Portinari, para Dom Qulxote, com poemas de Carlos Drummond de Andrade, sobre 0 clássico de Miguel de Cervantes Saavedra

5 Fernando Pessoa, Obra Poética, Rio de janeiro, Aguilar, 1969 pp. 356-7.

6 Cervantes, op. cit., p. 628. 
comparações pretensamente cultas e estandardizadas. Diz-se da condição quixotesca na luta contra objetivos ideais. Lá, na representação abstrata, a luta se faz contra objetivos construídos em cima da loucura. Idéias, porque tudo o que se pensa tem sua base na idealização antecedente a toda e qualquer ação, apenas por isso. Enquanto que na prosa da vida a luta é a dificuldade imediata da realidade concreta, mesmo que distante como finalidade, movida não pela loucura mas pela insubordinação às regras do senso comum. Nesse caso, luta honrosa muito embora inglória quase sempre, naquele, conseqüência ironicamente construída para demonstração da interioridade artística. Além do que não se coaduna à imagem do cavaleiro andante dos tempos modernos, escolhendose o caricato e falso ideal de luta impossível, deixando-se de lado procedimentos do personagem Dom Quixote que invalidam a metáfora que se alegorizou há muito. Como exemplo, este trecho do cap. XVII, 2 ${ }^{\mathrm{a}}$ parte, quando de Cavaleiro da Triste Figura transforma-se no valoroso Cavaleiro dos Leões:

“E, voltando-se para Sancho, pediu-lhe o elmo; e Sancho, não tendo ensejo de tirar os requeijões; deu-lho como estava. Pegou-lhe Dom Quixote e, sem ver o que vinha dentro, encaixou-o a toda pressa na cabeça, e como os requeijões se espremeram e apertaram, começou a correr o soro por todo o rosto e barbas de Dom Quixote, o que o assustou por tal forma, que disse para Sancho:

- Que será isto, Sancho? parece que me amoleceu o crânio, e se derreteram os miolos, ou que suo dos pés à cabeça; e, se suo, não é de medo de certo, será terrível a aventura que me vai suceder, dá-me, se tens, alguma coisa com que me limpe, que o copioso suor já me cega os olhos!'(7).

Em tempo de encerrar note-se a ironia da luta impossível contra as realidades distintas do mundo artístico e real que ultrapassam esse embate transformando-os em quimeras poéticas. Muito embora aquele que deveria ser o representante da poesia do eu fez a prosa da vida, mas isso, para quem faz essa distinção, não tem a menor importância, tudo é "poesia" e o artista "poeta" mesmo quando tem um projeto muito claro:

“(...) pois não foi outro meu intento, senão o de tornar aborrecidas dos homens as fingidas e disparatadas histórias dos livros de cavalarias, que já vão tropeçando com as do meu verdadeiro Quixote, e ainda hão de cair de todo, sem dúvida"(8).

Nesse final do romance ainda que por um recurso narrativo, sejam palavras de Cide Hamete Benengeli, o Cervantes de certo modo implícito. $\mathrm{O}$ autor explícito é o narrador do romance, isto é, aquele que explicitamente conduz a massa narrada, o implícito é aquele autor que nós supomos que ele seja ou tenha sido. O "quixotismo" já faz parte de uma curiosa transmutação de autor e personagem, seria ấ o Quixote implícito, aquele que se supõe que seja. No entanto a própria questão anterior da prosa da vida leva a esse tipo de raciocínio, o que deveria ser levado em conta por parte dos quixotescos que lutam com as armas dos seus inimigos.

Como todas essas questões, afinal, de um modo ou de outro, contribuem para o permanente florescer da arte, façamos como o autor:

$$
\text { (...) "Deus te dê saúde, e se não esqueça de mim. Vale"(9). }
$$

\section{BIBLIOGRAFIA}

ARISTÓTELES. "Poética”, in Os Pensadores. Trad. Eudoro de Souza. São Paulo, Abril Cultural, 1989, v. 2. AUERBACH, E. Mimesis. Trad. Suzi Frankl Sperber. São Paulo, Perspectiva, 1971.

BENJAMIN, W. "O Narrador - Observaçôes sobre a obra de Nikolai Leskov", in Os Pensadores. Trad. Erwin Theodor Rosenthal. São Paulo, Abril Cultural, 1980, v. 48.

HAMBURGER, K. A L Logica da Criação Literária. 2ª ed. Trad. Margot P. Malnic. São Paulo, Perspectiva, 1986. HEGEL, G. W. F. "L'Idée et l'Idéal", in Esthétique. Trad. J. G. Aubier. Paris, Ed. Montaigne, 1944, tome I. . Développement De L'Ideal Et Sa Différenciation En Formes D'Art Particulierres, idem, tome II. tome III, Ire partie. A - Les Arts Plastiques: Architecture, Sculpture. B - Les Arts Romantiques: Peinture, Musique. Idem,

\section{tome III, Ire partie.}

Les Arts Romantiques (suite)/ La Poésie. Trad. S. Jankélévitch. Idem, tome III, IIre partie. The Phenomenology of Mind. Translated by J. B. Baillie. New York, Harper Torchbooks, 1988.

7 Idem, ibidem, p. 535.

8 Idem, ibidem, p. 857.

9 Idem, ibidem, p. 30
HORÁCIO. Arte Poética. Trad. R. M. Rosado Fernandes. Lisboa, Livraria Clássica, col. Bilingue, s/d.

KANT, I. The Critique of Judgement. Translated by James Creed Meredith. New York, Oxford University, 1988.

MARX, K. La Ideologia Alemana. Trad. Wenceslao Roces. Barcelona, Ed. Pueblos Unidos/Grijalbo, 1970.

PLATAO. A República. Trad. Leonel Vallandro. Rio de Janeiro, Ediçōes de Ouro, s/d.

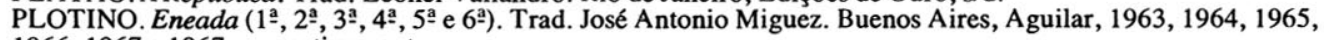
1966, 1967 e 1967 , respectivamente. 